\title{
Combining ASTER multispectral imagery analysis and support vector machines for rapid and cost-effective post-fire assessment: a case study from the Greek wildland fires of 2007
}

\author{
G. P. Petropoulos ${ }^{1}$, W. Knorr ${ }^{1}$, M. Scholze ${ }^{1}$, L. Boschetti ${ }^{2}$, and G. Karantounias ${ }^{3}$ \\ ${ }^{1}$ University of Bristol, Department of Earth Sciences, Wills Memorial Building, Queens Road, BS8 1RJ, Bristol, UK \\ ${ }^{2}$ Department of Geography, University of Maryland, 2181 LeFrak Hall, College Park, MD 20740, USA \\ ${ }^{3}$ Agricultural University of Athens, Department of Natural Resources Development and Agricultural Engineering, 75, Iera \\ Odos St., 118 55, Athens, Greece
}

Received: 30 September 2009 - Revised: 18 December 2009 - Accepted: 6 January 2010 - Published: 17 February 2010

\begin{abstract}
Remote sensing is increasingly being used as a cost-effective and practical solution for the rapid evaluation of impacts from wildland fires. The present study investigates the use of the support vector machine (SVM) classification method with multispectral data from the Advanced Spectral Emission and Reflection Radiometer (ASTER) for obtaining a rapid and cost effective post-fire assessment in a Mediterranean setting. A further objective is to perform a detailed intercomparison of available burnt area datasets for one of the most catastrophic forest fire events that occurred near the Greek capital during the summer of 2007. For this purpose, two ASTER scenes were acquired, one before and one closely after the fire episode. Cartography of the burnt area was obtained by classifying each multiband ASTER image into a number of discrete classes using the SVM classifier supported by land use/cover information from the CORINE 2000 land nomenclature. Overall verification of the derived thematic maps based on the classification statistics yielded results with a mean overall accuracy of $94.6 \%$ and a mean Kappa coefficient of 0.93. In addition, the burnt area estimate derived from the post-fire ASTER image was found to have an average difference of $9.63 \%$ from those reported by other operationally-offered burnt area datasets available for the test region.
\end{abstract}

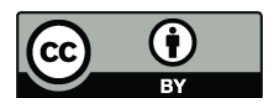

Correspondence to: G. P. Petropoulos (petropoulos.george@gmail.com)

\section{Introduction}

Wildland fires generally constitute one of the most widespread environmental hazards and are regarded as one of the dominant sources of disturbance in natural ecosystems, particularly in the Mediterranean basin (FAO, 2001). The high frequency of fires is a natural and recurrent element in the Mediterranean region and has been closely linked to the climatic conditions that dominate in these areas, characterised by prolonged drought periods generating favourable conditions for fire outbreaks (Cuomo et al., 2001; Zammit et al., 2006). Obtaining accurate as well as rapid mapping of burnt areas from a wildfire, is of key importance to environmental scientists and policy makers. Such information is important, for example, in estimating the economic consequences from the fire and in establishing rehabilitation and restoration policies in the affected areas to avoid post-fire hazards and long-term degradation (Giglio et al., 2006). Accurate knowledge of the geographical and temporal distribution of burning is also vital in being able to model the atmospheric and climatic impacts of biomass burning and assess the total emissions from it (Kaufmann et al., 1990; Kasischke et al., 1995). Delineation of the burnt area on an operational basis can also provide important information on land cover changes related to ecology and biodiversity, that in turn can significantly assist in understanding post-fire recovery of an affected area (Rong et al., 2004).

Remote sensing methods employed in burnt area mapping are based on a range of methodologies implemented in multispectral remote sensing data at diverse spatial resolutions. Methods that are used generally differ with regards to the type of processing carried out and the number

Published by Copernicus Publications on behalf of the European Geosciences Union. 
of the satellite scenes used in the analysis. Image processing methods employed for burnt area mapping in remote sensing utilise the changes in the reflective characteristics of vegetation and of their spectral signatures after burning, which results in a strong contrast of the fire-affected areas with the surrounding environment (Chuvieco et al., 1997; Jensen, 2000; van Wagtendonk et al., 2004; Lobola et al., 2007). While global and continental mapping of burnt areas has been conducted using time series of moderate resolution data (such as MODIS, SPOT VEGETATION or ATSR), generally processed through automatic systems (Simon et al., 2004; Tansey et al., 2008; Roy et al., 2005), high resolution applications have been typically based on single image processing. Processing methods vary from simple radiometric indices to other more complex ones such as image classification and sub-pixel classification methods such as pixel spectral unmixing. The use of image classification has proved a very practical technique for burnt area mapping in exploiting the spectral changes of the objects after a fire (Sunar and Ozkan, 2001; Epting et al., 2005; Kokaly et al., 2007; Escuin et al., 2008). For more details see Quintano et al. (2006) and Smith et al. (2007).

Non-parametric classifiers such as Artificial Neural Networks or the Spectral Angle Mapper have certain advantages over parametric ones, such as the Maximum Likelihood and the Mahalanobis Distance methods, an important one being that they do not require prior knowledge of the statistical distribution of the data to be classified. Support Vector Machines (SVM) non-parametric classifiers have the additional advantage that they are able to simultaneously minimize the empirical classification error and maximize the class separation using various transformations of hyperplanes. This allows SVM to better deal with data of high dimensionality and/or classes with a feature space of multimodal distribution producing often better results in comparison to other parametric or non-parametric methods (Waske and Benediktsson, 2007; Sanchez-Hernandez et al., 2007; van der Linden et al., 2007; Koetz et al., 2008; Dixon and Candade, 2008). SVM classifiers are also easy to implement, since only a few parameters need to be adjusted by the user (Karimi et al., 2006) and they have shown to generally provide good results when small training sets are used (Pal and Mather, 2006). SVM has been widely applied in many classification problems using remote sensing data (Brown et al., 1999; Zhu and Blumberg, 2002; Keuchel et al., 2003; Sanchez-Hernandez et al., 2007; Tseng et al., 2008; Koetz et al., 2008; Kavzoglu and Colkesen, 2009), including burnt area mapping implemented in SPOT5 multispectral data (Zammit et al., 2006).

Multispectral data from the Advanced Spaceborne Thermal Emission and Reflection Radiometer (ASTER ${ }^{1}$ ), the highest spatial resolution instrument onboard the Earth Observing system (EOS) Terra platform, have so far been ex-

\footnotetext{
${ }^{1}$ http://asterweb.jpl.nasa.gov/swir-alert.asp, last access: 30 September 2009
}

ploited in a large spectrum of fire analysis investigations. Such studies include fuel type mapping in various ecosystem conditions (Lasaponara and Lanorte, 2007; Falkowski et al., 2005), forest fire wildfire management (Keramitsoglou et al., 2008), assessment of forest fire risk (Guang-Xiong et al., 2007 ) and the evaluation of wildfire damage (Nomonoura et al., 2007). In addition, ASTER imagery has been used in the identification of coal fire location and change (Chen et al., 2007) as well as the detection and characterisation of active fire (Giglio et al., 2008) and the validation of active fire products computed from moderate resolution sensors such as MODIS (Giglio et al., 2003; Morisette et al., 2005a, b).

However, based on our knowledge, although the combined use of SVM with ASTER imagery analysis has been demonstrated in the past (Zhu and Blumberg, 2002), their combined use for retrieving burnt area estimates has not been investigated yet. But ASTER has a number of particular advantages that make it unique: on the one hand, its superior spatial $(15 \mathrm{~m}-90 \mathrm{~m})$ and spectral resolution (14 bands from visible to thermal infrared) compared to freely distributed data such as MODIS and, on the other hand, its low acquisition cost in contrast to other sensors of similar resolution. ASTER may, therefore, act as a "pathfinder" for evaluating the performance of analogous retrieval algorithms for performing a fire analysis - including burnt area mapping - implemented with coarser - resolution data, because its high spatial resolution makes it easier to compare to in situ observations for validation purposes.

The present work explores, for the first time, the value of the combined use of ASTER satellite data and SVM classifier for this purpose using them in a case study in one of the largest Greek forest fire events during the catastrophic fires season of year 2007. This includes a detailed intercomparison of burnt area estimates at a regional scale between those derived from the present study and data sources currently available for operational needs in forest fires in the Mediterranean region, ranging from $1 \mathrm{~m}$ to $1 \mathrm{~km}$ spatial resolution.

\section{Site description}

The severe forest fires of summer 2007 in the Mediterranean basin attracted sustained interest by the remote sensing community in mapping the extent of the burning using various methods and satellite sensors, particularly in Greece as this was the country mostly affected (Boschetti et al., 2008; Gitas et al., 2008; Sifakis et al., 2008; Kontoes et al., 2009). The study site comprises the area of Mt Parnitha, located approximately $30 \mathrm{~km}$ north of Athens, Greece (Fig. 1). The study area covers approximately $200 \mathrm{~km}^{2}$ with an altitude ranging from 200 to $1400 \mathrm{~m}$ a.s.l. and slopes ranging from 3 to $90 \%$. The study region is representative of the mixed characteristics of the eastern Mediterranean regions, covered by Greek Fir and Aleppo Pine forest at altitudes between $300 \mathrm{~m}$ and 


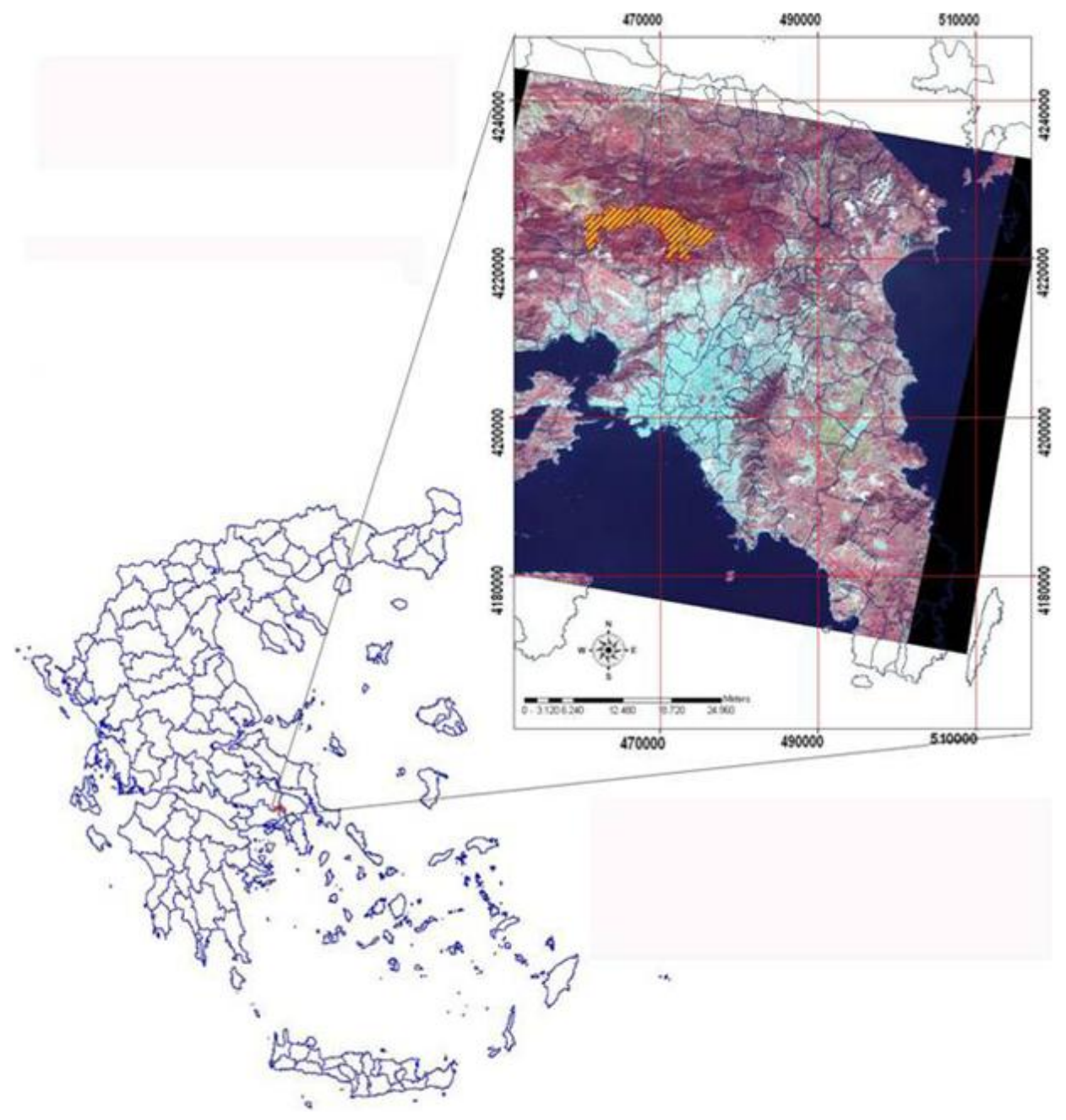

Fig. 1. Location of the study region.

$1000 \mathrm{~m}$. Above $1000 \mathrm{~m}$ height the dominant land types are grassland and scrubland, and below $300 \mathrm{~m}$ farmland (to the north) and suburban housing (to the east). In 1961, a large part of Mt Parnitha was designated as a national park and conservation site and was later also included to the European network of protected areas Natura 2000 due to its high biodiversity. The region also contains one of the few remaining forests near Athens and is, therefore, important for the city's microclimate. Mt Parnitha experienced severe damage from a wildfire outbreak on 28 June 2007, which was suppressed 5 days later (1 July 2007).

\section{Data description}

\subsection{ASTER data}

Multispectral remote sensing image data from the ASTER multispectral sensor was used as the primary source for analysing the fire in Mt Parnitha during the summer of
2007. Due to the known problem of ASTER shortwave (SWIR) bands on-board calibration which started to degrade the quality of the SWIR bands information of the sensor since 2007 (ASTER web site, 2009), the present uses are only for the ASTER visible and near infrared (VNIR) bands from ASTER the surface reflectance higher level product (15-m spatial resolution). This product consists of geometrically and atmospherically corrected VNIR reflectance data (Thome et al., 1999). Two ASTER images were obtained, one before (21 March 2004) and one soon after the fire suppression (20 July 2007). The selection of the specific images was based on the fulfillment of criteria such as clear atmospheric conditions, high sun conditions, low water vapour and near-nadir viewing and availability of the nearest ASTER data closest to the fire event. The images were obtained from the ASTER data distribution center in Japan (http://imsweb.aster.ersdac.or.jp/ims/html/MainMenu/ MainMenu.html). 


\section{Description of additional data}

Information on land use/cover from CORINE 2000 land nomenclature (JRC-EEA, 2005) was used to assist in the classification of the ASTER multispectral images CORINE 2000 data used in the present study were at a spatial resolution of $100 \mathrm{~m}$ and are available to the public at no cost).

In addition, burnt area estimates for the test region were obtained from independent sources, namely the World Wide Fund for Nature (WWF) Hellas, the RiskEOS Global Monitoring for Environmental Security/Service Element (GMES) of the European Space Agency (ESA), as well as from operational services available in Europe, namely the European Forest Fire Information System for Rapid Damage Assessment (EFFIS RDA) and the Moderate Resolution Imaging Spectroradiometer (MODIS) burnt area product. Estimates of the burnt area from WWF Hellas was done using primarily IKONOS ( $1 \mathrm{~m}$ spatial resolution, Pan-sharpened 4 bands dataset) satellite imagery analysis and their results were checked against field surveys (WWF Hellas, personal communication, 2007).

RiskEOS (http://www.risk-eos.com/actus/pge/index.php? arbo=0) was developed in the framework of the GMES-SE programme of ESA, which is a crisis response service to situations engendered by natural disasters. The burnt area mapping from the RiskEOS involves automatic production of highly accurate maps of burned area, derived from implementation of various spectral indices which are combined with a change vector analysis (see, for example, Kontoes et al., 2009). For the Mt Parnitha region, post-fire burning assessment analysis had been based on SPOT4 XS multispectral $20 \mathrm{~m}$ spatial resolution imagery, acquired shortly after the fire suppression (C. Kontoes, personal communication, 2009).

EFFIS has been in operation since 1997 by the Joint Research Centre (JRC) of the European Commission. Its main role is to provide the EU countries with a daily map of fire risk and to map any forest fires larger than 50 ha of each Mediterranean EU country. EFFIS RDA burnt area data are derived from the combination of MODIS VNIR and SWIR data $(250 \mathrm{~m}$ and $500 \mathrm{~m}$, respectively) and the MODIS $1-\mathrm{km}$ active fire product (Giglio et al., 2003) as well as various ancillary data (Barbosa et al., 2006). The evaluation estimates of the burnt area from the EFFIS RDA system is provided at a spatial resolution of $250 \mathrm{~m}$ (EC, 2006).

The MODIS burnt area product (MCD45A1) is a collection five product of the MODIS suite of land surface products (Justice et al., 2002; Roy et al., 2005, 2008). It includes monthly estimates of burnt area with a spatial resolution of $500 \mathrm{~m}$. This product is based on the detection of rapid change in MODIS Terra and Aqua sensor daily reflectance values, assisted by a bidirectional reflectance model which is used to correct angular effects and by statistical assumptions of change probability from a previously observed state (Roy et al., 2008).

\section{Methodology description}

\subsection{Support vector machines}

A summary of the basic principles of the SVM method is briefly made available here. A detailed description of the SVM technique can be found, for example, in Burges (1998) and Foody and Mather (2004). SVM is a supervised machine learning method that performs classification based on statistical learning theory (Vapnik, 1995). SVM is a binary classification method that provides a separation of classes by fitting an optimal separating hyperplane to a set of training data that maximizes the separation between the classes. Essentially, the hyperplane is the decision surface on which the optimal class separation takes place. Intuitively, a good separation is achieved by the hyperplane that has the largest distance to the neighbouring data points of both classes.

Each training example is represented by a feature vector. From a given set of training data, the SVM classifier calculates an optimal hyperplane characterised by a vector that provides the best separation between the two classes. The optimal hyperplane is the one that maximizes the distance between the hyperplane and the nearest positive and negative training example, called the margin. To avoid computational overload, this is not done by evaluating all training points, but only a subset, called the "support vectors" of the algorithm. In order to represent more complex shapes than linear hyperplanes, the classifier may use kernel functions which replace the vector. In this case, the problem transforms into an equivalent linear hyperplane problem of higher (sometimes infinite) dimensionality. Commonly used SVM kernels include polynomial and radial basis function (RBF), and sigmoid kernels. Also, a penalty parameter can be introduced to the SVM classifier to quantify the misclassification error, providing important information in the case of non-separable training datasets. Finally, SVM classifiers can be extended to more than two classes by splitting the problem into a series of binary class separations.

\subsection{Selection of the SVM parameters}

In the present study, multiclass SVM classification was performed in the ENVI (version 4.5) image processing environment. In ENVI, a pairwise classification strategy is used for performing a multiclass classification. This method is based on creating a binary classifier for each possible pair of classes, choosing the class that achieved the highest probability of identification across the series pair-wise comparisons assessed, based on a kernel. The selection of the kernel is regarded as the most important task in the implementation and the performance of the SVM classifier (e.g. Keuchel et al., 2003; Li and Liu, 2010). Here, the radial basis function (RBF) kernel was used. The RBF was chosen because it has been widely used in the literature in land classification and change detection studies with various satellite data (Keuchel 


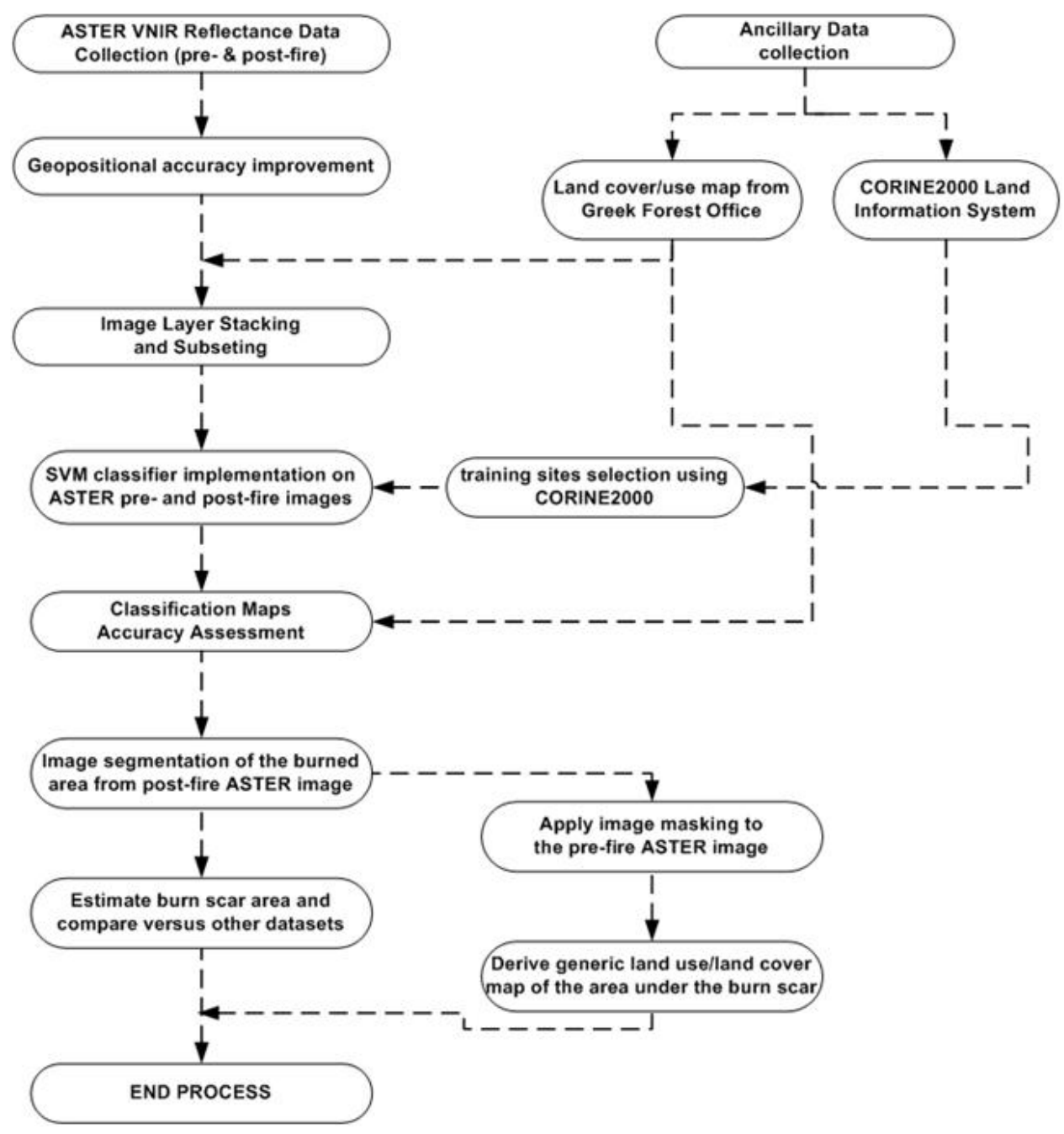

Fig. 2. Overall methodology followed for the implementation of the SVM technique to the ASTER imagery for deriving a post-fire assessment of the burning for the study region.

et al., 2003; Carrao et al., 2008; Knorn et al., 2009; Huang et al., 2008; Kuemmerle et al., 2009), including ASTER (Kavzoglou and Colkesen, 2009) and has shown classification results that have outperformed those obtained by other kernel types. In addition, RBF kernel requires only one parameter to be pre-defined, which makes it more robust in its implementation in contrast to other kernels (Huang et al., 2002, 2008). RBF kernel is defined as:

$K\left(x_{i}, x_{j}\right)=\exp \left(-\gamma\left\|\left(x_{i}, x_{j}\right)\right\|^{2}\right), \gamma>0$

where $x_{i}$ and $x_{j}$ represent a set of training data and $\gamma$ is a user-defined parameter, specified as the inverse of the number of the spectral bands of the sensor on which the SVM is implemented. The penalty parameter controls the tradeoff between allowing training errors and forcing rigid margins and it was set to its maximum value; we were interested in creating a more accurate model. The images were all processed at full resolution (i.e. pyramid parameter was set to zero). A classification probability threshold of zero was applied, meaning that all pixels were assigned exactly one class, and none remained unclassified.

\subsection{Burnt area delineation}

The image processing steps for retrieval of the burnt area and of the post-fire burning assessment from the two ASTER images are depicted in Fig. 2. Preliminary processing of the ASTER reflectance images included the improvement of the geopositional accuracy of each ASTER image (Abrams and Hook, 1999; LPDAAC, 2006), the data co-registration (layer stack) to the Universal Transverse Mercator (UTM) map projection system, and the creation of an image subset that included the area of interest. The geopositional accuracy of the dataset was verified by overlaying the geocorrected images to a vector layer $(1: 25000)$ that was available for the area. 
The mapping of the burnt area and the land use/cover types in the interior of the burn scar was obtained by classifying each ASTER imagery into a number of discrete classes based on the CORINE 2000 land nomenclature, which was further generalised into a smaller number of classes according to the characteristics and properties of the land use/cover types present in our study site. The classes which were selected included, apart from the burnt area, the urban/bare soil, the forest, scrubland and agricultural areas. Essentially, the two ASTER images included the same classes except that the class "burnt area" was not included in the pre-fire ASTER image.

To derive the land use/cover classes, the SVM nonparametric classifier was applied to each ASTER image. The algorithm was trained using a random sampling design of points, where an average of approximately 1500 and 3000 such points were chosen from the pre- and post-fire ASTER image, respectively, from each class based on the CORINE 2000 land nomenclature. Training points, specifically for the burnt area class, were obtained from visual inspection of the ASTER post-fire image itself, assisted by the IKONOS imagery from WWF Hellas study. Image segmentation, which was performed on the post-fire classification image, allowed the delineation of the burn scar from the image.

\subsection{Accuracy assessment}

Assessment of the SVM classifier performance in the ASTER images was based on the analysis of the classification statistics obtained from the two ASTER images. Classification accuracy of the derived classification maps was assessed via the error matrix. The latter was derived from a total of 2255 pixels (ca. 470 per class) used for validation and selected based on a random sampling design and the CORINE 2000 land nomenclature. From this we derived overall accuracy and the Kappa statistics (Foody, 2002). The producer's accuracy (100\% minus omission error) describes the probability of correct classification and refers to all pixels classified by the algorithm as a given class. The user's accuracy (100\% minus commission error) also describes the success rate, but is relating to all pixels belonging to a certain class according to the ground truth. The overall accuracy is the total number of pixels classified correctly, divided by the total number of pixels (Story and Congalton, 1986). The Kappa statistic provides a measure of the difference between the actual agreement between reference data and the classifier used in the present study to perform the classification versus the chance of agreement between the reference data and a randomly selected classifier (Congalton and Green, 1999).

\section{Results and discussion}

\subsection{ASTER SVM classification accuracy assessment}

The thematic map derived from the implementation of the SVM classifier to the ASTER pre- and post-fire imagery is depicted in Fig. 3 and the associated classification accuracy assessment statistics in Table 1. Overall, SVM supervised classification returned satisfactory results in terms of recognising the different classes at the $15-\mathrm{m}$ spatial resolution. Visual comparison of the derived classification maps against the land use/cover map from CORINE2000 map showed generally an acceptable similarity in the spatial distribution of the different land use/cover classes under the ASTER's fieldof-view. As seen, overall classification accuracy was $95.5 \%$ and $93.6 \%$ for the pre- and post-fire classification images, respectively, whereas the Kappa coefficient was 0.94 and 0.92 , respectively. Also, the producer's accuracy and user's accuracy for each of the classes used was always reported greater than $87.1 \%$ and $86.0 \%$, respectively, indicating the overall success of the performed classification. Furthermore, based on the supervised classification results of the post-fire ASTER image, the total area burnt was $46.49 \mathrm{~km}^{2}$.

With reference to the classification statistics of the ASTER post-fire image, as can be observed, the class "burnt area" was found to be correctly classified with no omission or commission errors among the 440 validation points used for this particular class. Also, a high producer's accuracy was found for the forests (100\%) and urban/bare soil class (94.9\%) in comparison to the scrublands $(87.1 \%)$ and agricultural areas $(87.2 \%)$. In addition, the user's accuracy was reported highest for the forests $(100 \%)$ and the agricultural areas $(93.5 \%)$ in comparison to urban/bare soil areas $(89.1 \%)$ and scrublands $(92.7 \%)$. Similar results were also obtained in the classification of the ASTER pre-fire image (see Table 1). High producer's and user's accuracies were reported for all classes, with the highest producer's accuracy found in the classification of urban/bare soil areas (99.4\%) and the scrublands $(95.3 \%)$, followed by forests $(92.8 \%)$ and agricultural areas $(91.7 \%)$. Forests exhibited the highest user's accuracy $(100 \%)$ from all classes, followed by and the urban/bare soil (98.0\%), agricultural areas (97.0\%) and scrubland (90.6\%). The level of the overall accuracy in both ASTER images is largely determined by the lower accuracy that exhibited the classification of scrublands (Table 1), which is assumed to be caused by mixed pixels between scrublands and forests and/or agriculture.

\subsection{Post-fire burning assessment}

The image segmentation implemented in the supervised classification of the post-fire ASTER image also allowed the delineation of the burned area envelope which was overlain on top of the classified pre-fire image, providing a cartography of the land use/land cover of the area under the 

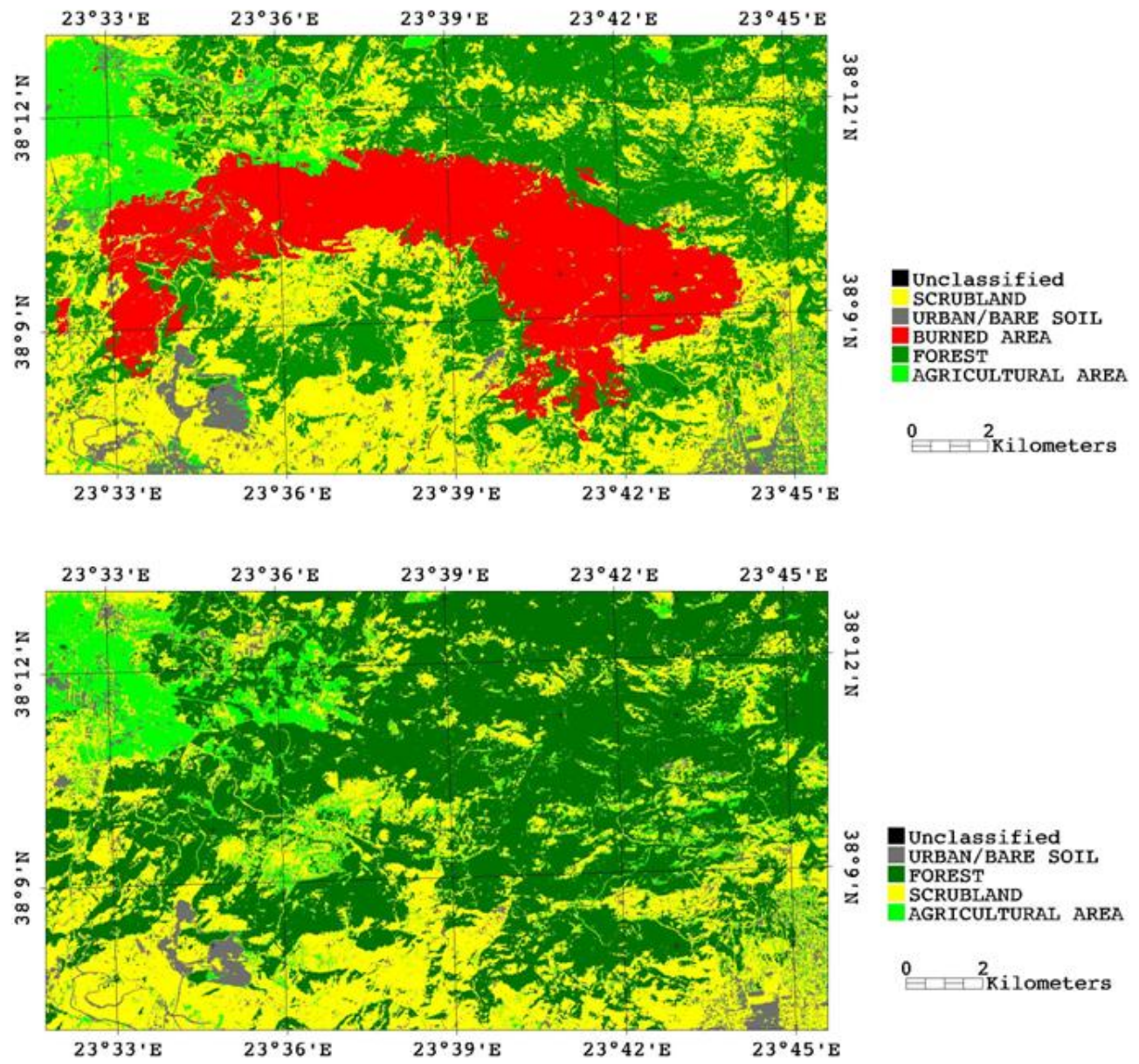

Fig. 3. Thematic maps produced from the implementation of the SVM classifier to the ASTER post-fire (top image) and the pre-fire (bottom) images.

Table 1. Summary of the classification statistics of the post-fire (top) and of the pre-fire (bottom) ASTER 15 reflectance images.

\begin{tabular}{|c|c|c|c|c|c|}
\hline & \multirow[b]{2}{*}{ Class name } & \multicolumn{4}{|c|}{ Support vector machines classification } \\
\hline & & $\begin{array}{r}\text { Commission } \\
\text { error }(\%)\end{array}$ & $\begin{array}{l}\text { Omission } \\
\text { error }(\%)\end{array}$ & $\begin{array}{c}\text { Producer's Accuracy } \\
(\%)\end{array}$ & $\begin{array}{c}\text { User's Accuracy } \\
(\%)\end{array}$ \\
\hline \multirow{7}{*}{ 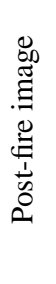 } & Scrubland & 7.35 & 12.90 & 87.10 & 92.65 \\
\hline & Urban/bare soil & 10.90 & 5.12 & 94.88 & 89.10 \\
\hline & Burnt area & 0.00 & 0.00 & 100.0 & 100.0 \\
\hline & Forests & 5.38 & 0.00 & 100.0 & 94.62 \\
\hline & Agricultural area & 6.50 & 12.77 & 87.23 & 93.50 \\
\hline & Overall Accuracy (\%) & 93.57 & & & \\
\hline & Kappa coefficient & 0.92 & & & \\
\hline \multirow{6}{*}{ 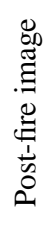 } & Scrubland & 0.00 & 7.23 & 92.77 & 100.0 \\
\hline & Urban/bare soil & 14.0 & 4.68 & 95.32 & 86.00 \\
\hline & Forests & 3.05 & 8.33 & 91.67 & 96.95 \\
\hline & Agricultural area & 2.00 & 0.58 & 99.42 & 98.00 \\
\hline & Overall accuracy (\%) & 95.52 & & & \\
\hline & Kappa coefficient & 0.94 & & & \\
\hline
\end{tabular}




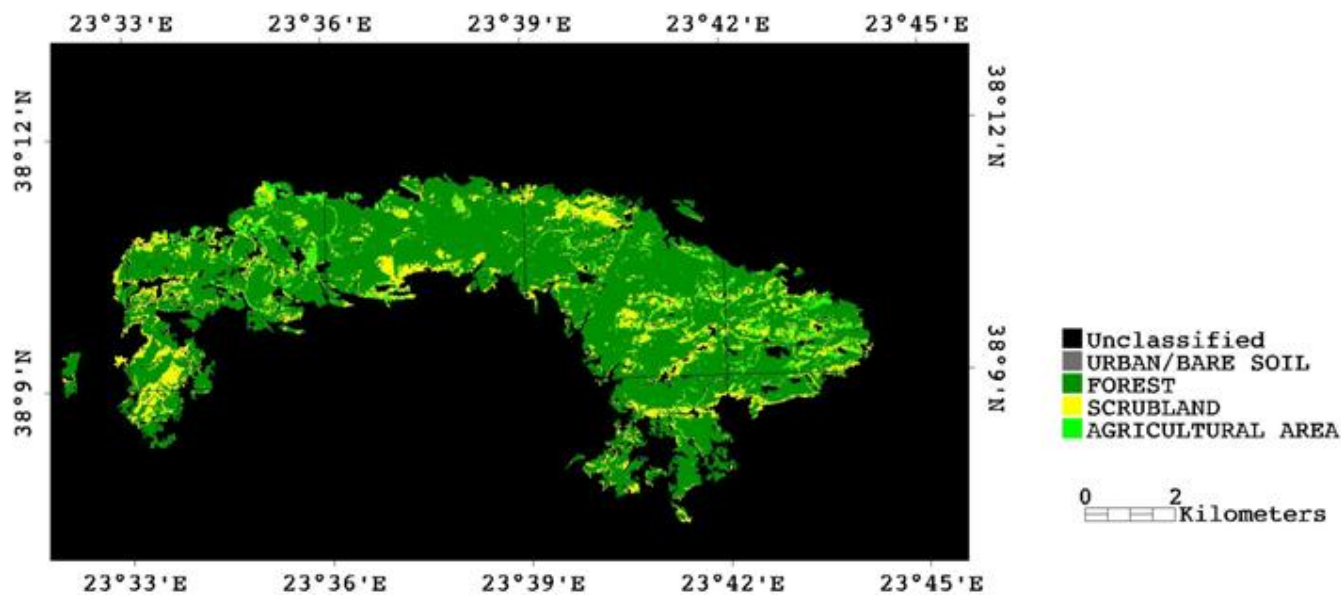

Fig. 4. Land use/land cover map of the area under the envelope of the burn scar.

Table 2. Results of the land use classes which were burnt in the wildfire in the study site as those derived from the fuel type map of the ASTER pre-fire supervised classification image using the SVM classifier.

\begin{tabular}{lcc}
\hline Land cover class & $\begin{array}{c}\text { ASTER-derived } \\
\left(\mathrm{km}^{2}\right)\end{array}$ & $\begin{array}{c}\% \text { of land class } \\
\text { type burnt }\end{array}$ \\
\hline Forest & 36.10 & 77.65 \\
Shrubland & 7.36 & 15.83 \\
Agricultural area & 2.94 & 6.32 \\
Urban/bare soil & 0.09 & 0.19 \\
Sum of burnt area & 46.49 & 100 \\
\hline
\end{tabular}

burn scar (Fig. 4). Table 2 illustrates the results from the quantitative estimates of the different land use/land cover classes under the burn scar envelope. Analysis of the results showed that from the total area burnt, $36.10 \mathrm{~km}^{2}$ of was forested area, $7.36 \mathrm{~km}^{2}$ scrublands, $2.94 \mathrm{~km}^{2}$ agricultural areas and $0.09 \mathrm{~km}^{2}$ urban/bare soil areas. The dominant burnt land use/land cover type was forests $(77.65 \%$ of total area burned), followed by scrublands $(15.83 \%$ of total area) and agricultural areas (6.32\% of total area), whereas urban/bare soils was the class burned least (only $0.19 \%$ of the total burned area).

\subsection{Burnt area estimates intercomparison}

The simultaneous availability of burnt area estimates for this specific fire from WWF Hellas, RiskEOS, EFFIS and MODIS burnt area products allowed an inter-comparison of the burnt-area estimates (Table 3). We note that this intercomparison is not regarded as a validation of the SVM classifier using the ASTER observation; it is rather an exploratory investigation of the deviations in the burnt area estimates between the different datasets and reflects the uncertainties in remotely sensed burnt area estimates. As shown in Fig. 5, in all cases the shape of the detected burnt scar from the $15-\mathrm{m}$ ASTER reflectance imagery agreed well with those from the other datasets, indicating a good spatial agreement. In absolute terms, the ASTER-derived burnt area was in close agreement with the corresponding values from the other datasets. However, the estimate from ASTER and SVM is in much closer agreement with the RiskEOS and the WWF Hellas study estimated values, while it is noticeably higher from the MODIS burnt area product. Absolute difference in burnt area estimates ranged from 0.81 to $11.76 \mathrm{~km}^{2}$, with a mean of $9.63 \mathrm{~km}^{2}$ (equivalent to $9.63 \%$ ), whereas with the exception of the EFFIS data, the ASTER burnt area estimate is always lower. EFFIS RDA indeed provides a lower estimate of burnt area in comparison to the other datasets, including that of the MODIS burnt area product. Boschetti et al. (2008) in their study reported an overestimation of the MODIS results in comparison to the EFFIS RDA data by approximately $7 \%$, for the same fire season of 2007 in Greece. Disagreement in the burnt area estimates was suggested by the authors to be the result of the difference in the border lines defined between the datasets, and the fact that no agricultural regions and small fires had been included in the EFFIS burnt area estimates.

\section{Discussion}

The main finding from the reported results here is that ASTER imagery can be used with an SVM classifier and information from the CORINE 2000 land nomenclature to provide an accurate and rapid mapping of the land use/cover types distribution with very high accuracy levels. Others (e.g. Yuksel et al., 2008) recently demonstrated the synergic use of ASTER imagery with information from the CORINE 
Table 3. Comparisons of the burnt area estimates derived from ASTER post-fire imagery versus those derived from different datasets.

\begin{tabular}{lccc}
\hline & $\begin{array}{c}\text { Burnt area } \\
\left(\mathrm{km}^{2}\right)\end{array}$ & $\begin{array}{c}\text { Abs. Diff. from ASTER } \\
\left(\mathrm{km}^{2}\right)\end{array}$ & $\begin{array}{c}\text { Abs. \% diff. from ASTER } \\
\text { ASTER (15 m spatial resolution) }\end{array}$ \\
RiskEOS (20 m spatial resolution) & 46.49 & - & - \\
WWF Greece (1 m spatial resolution) & 47.30 & 0.81 & 1.73 \\
EFFIS RDA (250 m spatial resolution) & 49.20 & 2.71 & 5.83 \\
MODIS burnt area product (500 m spatial resolution) & 53.86 & 2.63 & 5.66 \\
\hline
\end{tabular}

land nomenclature for deriving land use/land cover maps in a Mediterranean setting, whereas in other studies the usefulness of CORINE data for fire analysis with coarser spatial resolution data has also been demonstrated in comparison to ASTER (e.g. Sifakis et al., 2004).

Generally, in terms of the overall accuracy and Kappa coefficient, accuracy levels reported here are also comparable to those reported by Zhu and Blumberg (2002), who demonstrated the combined use of ASTER with SVM for land use/land cover mapping for a site in Israel using six classes. In addition, results reported here are in close agreement with other studies performed using ASTER data with nonparametric classification methods (Lasaponara and Lanorte, 2007; Keramitsoglou et al., 2008), studies where SVM classifier has been combined within hyperspectral and/or LiDAR data (Koetz et al., 2008) and/or studies where SVM have been used for land cover mapping applications in dissimilar ecosystem conditions (e.g. Keuchel et al., 2003; Karimi et al., 2006; Dixon and Candade, 2008; Kavzoglu and Colkensen, 2009; Su, 2009).

Taking into account the classification accuracy of the prefire ASTER image and the fact that no fire occurred between 2004-2007 (validated from both the EFFIS and local authorities), the ASTER results concerning the land use/land covers under the burn scar area appear reasonable. It is also worthwhile to note that the summed areas of the forest and scrubland classes derived from the SVM and ASTER method was in close correspondence to the EFFIS reported burned area estimate, which by definition covers only areas classified as "forest" (absolute difference is $0.4 \mathrm{~km}^{2}$ ). Unfortunately, these results could not be directly compared against other datasets as such data were not available for the region from other sources. Yet, overall results further demonstrated the synergy between ASTER and CORINE 2000 to perform a post-fire assessment of the burning in the affected area using the SVM with the ASTER imagery analysis.

There are many possible reasons accountable for the differences in the burnt area estimates between the datasets compared here, including the differences in their spatial and temporal resolutions as well as in the relative methodologies employed for the burnt area retrieval. IKONOS satellite imagery used in the study conducted by WWF Hellas has a spatial resolution of $1 \mathrm{~m}$, RiskEOS estimate was based on SPOT4 XS (20 m) imagery analysis (Kontoes et al., 2009), whereas the EFFIS and the MODIS burnt area product data have a spatial resolution of $250 \mathrm{~m}$ and $500 \mathrm{~m}$, respectively. The lower spatial resolution, combined with the fragmentation of the burned areas evident from Fig. 3, introduces an amount classification errors which, it can be argued that are due to, are due solely to the sensor resolution (Boschetti et al., 2003). Furthermore, discrepancy in the burnt area estimates between the different sensors can be enlarged by the heterogeneity of the burnt surface as non-burnt areas can be included in the coarse resolution burnt scar estimates leading to overestimation of the burnt area due to spectral confusion and overlapping (Chuvieco and Congalton, 1989). Moreover, it should be noted that EFFIS RDA burnt area results include only the estimates of the forested area burnt in the total burnt area reported, in contrast to other datasets which include estimates of all land use/cover types burnt. Also, it should be pointed out that in the EFFIS estimate, an error due to the generalisation of the fire vector map should perhaps also be added, as non-burnt areas inside the burnt scar (which were identified by the other datasets) have been marked as burnt on the EFFIS vector map.

\section{Conclusions}

This study investigated the suitability of the SVM classifier for the analysis of ASTER multispectral imagery for the rapid and economically viable assessment of impacts from wildfires. As a case study, one of the most catastrophic Greek forest wildfires occurred in summer 2007 was used. This work, to our knowledge, forms the first implementation of the combined use of the SVM classifier with ASTER multispectral satellite imagery for obtaining burnt area mapping and performing post-fire analysis assessment. It also provided the first intercomparison of burnt area datasets available in the Mediterranean region derived from spaceborne systems of dissimilar spatial resolution from different largescale operational sources (i.e. EFFIS, RiskEOS and MODIS burnt area products). 

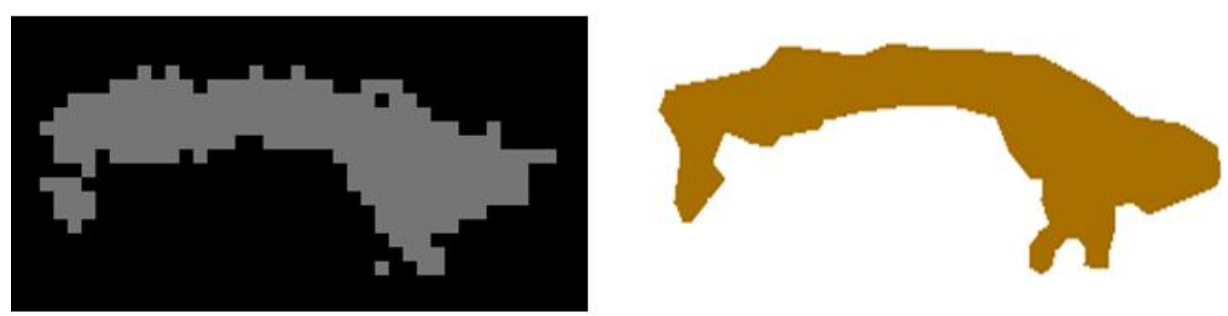

(a)

(b)
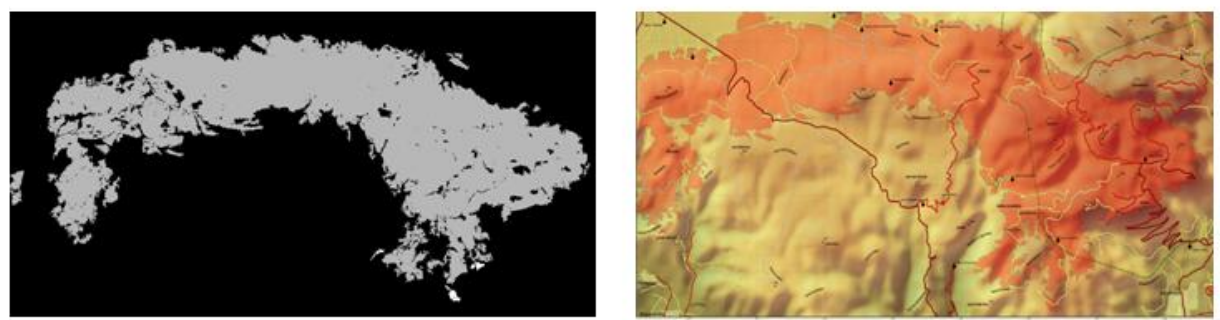

(c)

(d).

Fig. 5. Examples of the burnt scar shape from the fire event occurred in the studied, (a) MODIS burned area product, (b) EFFIS, (c) ASTER, and (d) IKONOS, as computed by the different sources used in this study (from WWF study, available at: http://www.wwf.gr/index.php? option=com_content $\backslash \&$ task=view $\backslash \&$ id=539 $\backslash$ \&itemid=294).

Overall, the 15-m ASTER spatial resolution proved suitable for performing a fire analysis at the regional scale of this specific fire episode, providing a mapping of the burnt area and of the generic land use/land cover types affected by the fire under the enclosed burnt area perimeter. Accuracy assessment of the computed classification maps using established classification statistical metrics indicated a mean overall accuracy of $94.6 \%$ and a mean Kappa coefficient of 0.93 , providing results of comparable accuracy levels compared to other analogous studies that have demonstrated the use of SVM in classification problems (Zhu and Blumberg, 2002; Kavzoglu and Colkensen, 2009). Thus, overall results clearly suggested that ASTER imagery can be used with an SVM classifier methodology to provide accurate and rapid analysis and characterisation of the land cover/use classes distribution. The synergy between ASTER and CORINE2000 to construct a fire map from the pre-fire ASTER image of the envelope inside the burnt area using an SVM classification method was also demonstrated. ASTER resolution yielded results of the burnt scar estimates comparable to those obtained from inventories obtained by WWF Hellas, RiskEOS, EFFIS Rapid Damage Assessment system and the MODIS burnt area products. The average difference in burnt area estimate from ASTER and those from the other sources was $4.48 \mathrm{~km}^{2}$ or equivalently $9.63 \%$, confirming the validity of these datasets (including the EFFIS RDA and MODIS burnt area product) for operational fire mapping applications.
Generally, our results suggested that the methodology employed here has the potential to be used for providing key information in a rapid and cost-effective post-fire assessment on a regional scale of a comparatively high resolution sufficient for the needs of local authorities. Such information can assist the decision making process in fire risk management in prioritisation of areas for rehabilitation as well as for maintaining a history of fire episodes in the specific region. This is especially important when taking into account the significance of fire events in Greece in ecological, environmental, social as well as cultural/historical context. Although the capacity of the work described in this communication has been restricted to illustrating the ability of ASTER sensor in performing a rapid and cost effective fire analysis of a single fire event, the motivation of this study stems from our goal of extending the methodology presented herein to other Mediterranean-like ecosystems in performing rapid and cost effective post-fire analysis.

Acknowledgements. We wish to thank Giorgio Libertà and the EFFIS team at Joint Research Center (JRC), Italy for the rapid provision of the EFFIS vector files concerning the Greek forest fires of year 2007 as well as Liarikos from WWF Hellas and Kontoes from the National Observatory of Athens, Greece for the fruitful discussions on their studies for Mt Parnitha region. In addition, we would like to thank the Head of the Directorate General for Development and Protection of Forest of the Greek Ministry of Agricultural Development and Food, as well as the Head of 
the Parnitha Forest Office and Head of Thebes Forest Office for providing us with the administration inventory burnt area results as well as the 1:25000 land use/cover thematic map of Mt Parnitha.

Edited by: R. Lasaponara

Reviewed by: A. Elatawneh and Y. Chang

\section{References}

Abrams, M. and Hook, S.: ASTER User Handbook, Jet Propulsion Laboratory \& EROS data centre, 135 pp., available at: http://asterweb.jpl.nasa.gov/content/03_data/04_Documents/ aster_user_guide_v2.pdf(last access: 14 April 2009), 1999.

Barbosa, P., Kucera, J., Strobi, P., Vogt, P., Camia A., and SanMiguel, J.: European Forest Fire Information System (EFFIS) - rapid damage assessment: appraisal of burnt area maps in southern Europe using MODIS data (2003-2005), Forest Ecol. Manag., 232, Supp. 1, p. S218, 2006.

Boschetti, L., Flasse, S., and Brivio, P. A.: Analysis of the conflict between omission and commission in low spatial resolution thematic products: the Pareto Boundary, Remote Sens. Environ., 91(3-4), 280-292, 2003.

Boschetti, L., Roy, D., Barbosa, P., Boca, R., and Justice, C.: A MODIS assessment of the summer 2007 extent burnt in Greece, Int. J. Remote Sens., 29(8), 2433-2436, 2008.

Brown, M., Gunn, S. R., and Lewis, H. G.: Support vector machines for optimal classification and spectral unmixing, Ecol. Model., 120, 167-179, 1999.

Burges, C.: A tutorial on support vector machines for pattern recognition, Data Min. Knowl. Disc., 2(2), 121-167, 1998.

Carrao, H., Concalves, P., and Caetano, M..: Contribution of multispectral and multitemporal information from MODIS images to land cover classification, Remote Sens. Environ., 112, 986-997, 2008.

Chen, Y., Jing, L., Bo, Y., Shi, P. and Zhang, S.: Detection of coal fire location and change based on multi-temporal thermal remotely sensed data and field measurements, Int. J. Remote Sens., 28(15), 3173-3179, 2007.

Chuvieco, E. and Congalton, R. G.: Application of remote sensing and geographic information systems to forest fire hazard mapping, Remote Sensing of the Environment, 29, 147-159, 1989.

Chuvieco, E., Salas, J., and Vega, C.: Remote sensing and GIS for long-term fire risk mapping, in: A review of remote sensing methods for the study of large wildland fires, edited by: Chuvieco, E., Mega fires Project ENV-CT96-0256, Alcala de Henares, Spain, 91-108, 1997.

Congalton, R. G. and Green, K.: Assessing the Accuracy of Remotely Sensed Data: Principles and Practices, Lewis, New York, 1999.

Cuomo, V., Lasaponara, R., and Tramutoli, V.: Evaluation of a new satellite-based method for forest fire detection, Int. J. Remote Sens., 22(9), 1799-1826, 2001.

Dixon, B. and Candade, N.: Multispectral land use classification using neural networks and support vector machines: one or the other, or both?, Int. J. Remote Sens., 29(4), 1185-1206, 2008.

EC: Forest Fires in Europe, European Commission, Joint Research Center, Institute for Environment and Sustainability, Report No 6, EUR 22312 EN, Italy, 2006.
Epting, J., Verbyla, D., and Sorbel, B.: Evaluation of remotely sensed indices for assessing burn severity in interior Alaska using Landsat TM and ETM+, Remote Sens. Environ., 96, 328-339, 2005.

Escuin, S., Navaro, R., and Fernandez, P.: Fire severity assessment by using NBR (Normalised Burn ratio) and NDVI (Normalised Difference Vegetation Index) derived from LANDSAT Landsat TM/ETM images, Int. J. Remote Sens., 29(4), 1053-1073, 2008.

Falkowski, M. J., Gessler, P. E., Morgan, P., Hudak, A. T., and Smith, A. M. S.: Characterising and mapping forest fire fuels using ASTER imagery and gradient modeling, Forest Ecol. Manag., 217, 129-146, 2005.

FAO: Global forest fire assessment 1990-2000, Forest Resources Assessment Programme, Working Paper No. 55, available at: http://www.fao.org/forestry/fo/fra/docs/Wp55_eng.pdf(last access: 14 April 2009), 2001.

Foody, G. M.: Status of land cover classification accuracy assessment, Remote Sens. Environ., 80, 185-201, 2002.

Foody, G. M. and Mather, A.: A relative evaluation of multiclass image classification by support vector machines, IEEE T. Geosci. Remote Sens., 42, 1335-1343, 2004.

Giglio, L., Csizar I., Restas, A., Morisette, J. T., Schroede, W., Morton, D., and Justice, C. O.: Active fire detection and characterization with the advanced spaceborne thermal emission and reflection radiometer (ASTER), Remote Sens. Environ., 112(6), 3055-3063, 2008.

Giglio, L., Descloitres, J., Justice, C. O., and Kaufman, Y. J.: An enchased contextual fire detection algorithm for MODIS, Remote Sens. Environ., 87, 273-282, 2003.

Giglio, L., van der Werf, G. R., Randerson, J. T., Collatz, G. J., and Kasibhatla, P.: Global estimation of burned area using MODIS active fire observations, Atmos. Chem. Phys., 6, 957-974, 2006, http://www.atmos-chem-phys.net/6/957/2006/.

Gitas, I. Z., Polychronaki, A., Katagis, T., and Malinis, G.: Contribution of remote sensing to isaster management activities: A case study of the large fires in the Peloponnese, Greece, Int. J. Remote Sens., 29(6), 1847-1853, 2008.

Guang-Xiong, P., Jing, L. Yun-hao, C., and Abdul-Patah, N.: A forest fire risk assessment using ASTER images in Peninsular Malaysia, Journal of China University of Mining and Technology, 17(2), 232-237, 2007.

Huang, C., Davis, L. S., and Townshend, J. R. G.: An assessment of support vector machines for land cover classification, Int. J. Remote Sens., 23, 725-749, 2002.

Huang, C., Song, K., Kim, S., Townshend, J. R. G., Davis, P., Masek, J. G., and Goward, S. N.: Use of dark object concept and support vector machines to automate forest cover change analysis, Remote Sens. Environ., 112, 970-985, 2008.

Jensen, J. R.: Remote Sensing of the Environment: An Earth Resource Perspective, Prentice Hall: Saddle River, NJ, 2000.

JRC-EEA: CORINE land cover updating for the year 2000: image 2000 and CLC2000, in: Products and Methods. Report EUR 21757 EN, edited by: Lima, V., JRC-Ispra, CORINE data are available at: http://reports.eea.europa.eu/COR0-landcover/ en(last access: 28 November 2009), 2005.

Justice, C. O., Townshen, D., Vermote, E. F., Masuoka, E., Wolfe, R. E., Saleous, N., Roy, D. P., and Morisette, J. T.: An overview of MODIS Land data processing and product status, Remote Sens. Environ., 83, 3-15, 2002. 
Karimi, Y., Orasher, S. O., Patel, R. M., and Kim, S. H.: Application of support vector machine technology for weed and nitrogen stress detection in corn, Comput. Electron. Agr., 51, 99-109, 2006.

Kasischke, E. S., French, N. F., Bourgeau-Chavez, L. L., and Christensen, N. L.: Estimating release of carbon from 1990 and 1991 forest fires in Alaska, J. Geophys. Res., 100, 2941-2951, 1995.

Kaufman, Y. J., Tucker, C. J., and Fung, I.: Remote sensing of biomass burning in the tropics, J. Geophys. Res., 95, 9927-9939, 1990.

Kavzoglou, T. and Colkesen, I.: A kernel functions analysis for support vector machines for land cover classification, Int. J. Appl. Earth Obs., 11, 352-359, 2009.

Kavzoglu, T. and Colkesen I.: A kernel functions analysis for support vector machines for land cover classification, Int. J. Appl. Earth Obs., 11, 352-359, 2009.

Keramitsoglou, I., Kontoes, C., Sykioti, O., Sifakis, N., and Xofis, P.: Reliable, accurate and timely forest mapping for wildfire management using ASTER and Hyperion satellite imagery, Forest Ecol. Manag., 255, 3556-3562, 2008.

Keuchel, J., Naumann, S., Heiler, M., and Siegmund, A.: Automatic land cover analysis for Tenerife by supervised classification using remotely sensed data, Remote Sens. Environ., 86, 53-541, 2003.

Knorn, J., Rabe, A., Radeloff, V. C., Kuemmerle, T., Kozak, J., and Horstert, P.: Land cover mapping of large areas using chain classification of neighboring Landsat satellite images, Remote Sens. Environ., 113, 957-964, 2009.

Koetz, B., Morsdoff, F., Linden, S., Curt, T., and Allogower, B.: Multi-source land cover classification for forest fire management based on imaging spectrometry and LiDAR data, Forest Ecol. Manag., 256(3), 263-271, 2008.

Kokaly, R. F., Rockwell, B. W., Haire, S. L., and King, T. V.: Characterisation of post-fire surface cover, soils and burn severity at the Cerro Grande Fire, New Mexico, using hyperspectral and multispectral remote sesing, Remote Sens. Environ., 106, 305325, 2007.

Kontoes, C. C., Poilve, H., Florsch, G., Keramitsoglou, I., and Paralikidis, S.: A comparative analysis of fixed thresholding vs a classification tree approach for operational burn scar detection and mapping, Int. J. Appl. Earth Obs., 11(5), 299-316, available at: http://www.risk-eos.com/actus/pge/index.php?arbo=0, last access: 28 November 2009.

Kuemmerle, T., Chaskovskyy, O., Knorn, J., Radeloff, V. C., Kruhlov, I., Keeton, W. S., and Hostert, P.: Forest cover change and illegal logging in the Ukrainian Carpathians in the transition period from 1988 to 2007. Remote Sens. Environ., 113, 1194$1207,2009$.

Lasaponara, R. and Lanorte, A.: Remotely sensed characterisation of forest fuel types by using satellite ASTER data, Int. J. Appl. Earth Obs., 9, 225-234, 2007.

Li, D.-C. and Liu, C.-W.: A class possibility based kernel to increase classification accuracy for small data sets using support vector machines, Expert Syst. Appl., 37, 3104-3110, 2010.

Li, R. R. Kaufman, Y. J, Hao, W. M., Salmon, J. M., and Gao, B.-C.: A technique for detecting burn scars using MODIS data., IEEE T. Geosci. Remote Se., 42(6), 1300-1308, 2004.

Lobola, T., Neal, K. J., and Csisar, I.: Regionally adaptable dNBRbased algorithm for bunred area mapping from MODIS, Remote
Sens. Environ., 109, 429-442, 2007.

LPDAAC: Land Processes Distributed Active Archive centre: GeoReferencing ASTER Level-1B Data: General Overview and Examples of Particular COTS Packages and Public Domain Software, available at: http://edcdaac.usgs.gov/aster/ASTER_ GeoRef_FINAL.pdf(last access: 4 April 2009), 2006.

Morisette, J. T., Giglio, L., Csiszar, I., and Justice, C. O.: Validaiton of the MODIS active fire product over Southern Africa with ASTER data, Int. J. Remote Sens., 26(19), 4239-4264, 2005a.

Morisette, J. T., Giglio, L., Csiszar, I., Setzer, A., Schroeder, W., Morton, D., and Justice, C. O.: Validiaiton of MODIS active fire detection products derived from two algorithms, Earth Interact., 9, 1-25, 2005b.

Nonomoura, A., Masuda, T., and Moriya, H.: Wildfire damage evaluation by merging remote sensing with a fire area simulation model in Naoshima, Kagawa, Japan, Landsc. Ecol. Eng., 3, 109-117, 2007

Pal, M., and Mather, P. M.: Some issues in the classification of DAIS hyperspectral data, Int. J. Remote Sens., 27, 2895-2916, 2006

Quintano, C., Fernandez-Manso, A., Fernandez-Manso, O., and Shimabukuro, Y. E.: Mapping burnt areas in Mediterranean countries using spectral mixture analysis from a uni-temporal perspective, Int. J. Remote Sens., 27(4), 645-662, 2006

Roy, D. P., Boschetti, L., Justice, C. O., and Ju, J.: The collection 5 MODIS burnt area product - Global evaluation by comparison with the MODIS active fire product, Remote Sens. Environ., 112(9), 3690-3707, available at: http://modis-fire.umd.edu/ products.asp(last access: 28 November 2009), 2008.

Roy, D. P., Jin, Y., Lewis, P. E., and Justice, C. O.: Prototyping a global algorithm for systematic fire affected area mapping using MODIS time series data, Remote Sens. Environ., 97, 137-162, 2005.

Sanchez-Hernandez, C., Boyd, D. S., and Foody, G. M.: Mapping specific habitats from remotely sensed imagery: Support vector machine and support vector data description based classification of coastal saltmarsh habitats, Ecol. Inform., 2, 83-88, 2007.

Sifakis, D. P. and Keramitsoglou, I.: Combining AVHRR imagery with CORINE land cover data to observe forest fires and to assess their consequences, Int. J. Appl. Earth Obs., 5 (4), 263-274, 2004.

Sifakis, N., Iosifidis, C., and Kontoes, C.: Fire detection and monitoring over Greece in 2007 summer period using MSG satellite data, Geophysical Research Abstracts, EGU 2008-A-03989, 2008.

Simon, M., Plummer, S., Fierens, F., Hoeltzemann, J. J., and Arino, O.: Burnt area detection at global scale using ATSR-2: the Globscar products and their qualification, J. Geophys. Res., 109, D14S02, doi:10.1029/2003JD003622, 2004.

Smith, A. M. S, Drake, N. A., Wooster, M. J., Hudak, A. T., Holden, Z. A., and Gibbons, C. J.: Production of Landsat ETM+ reference imagery of burnt areas within Southern African savannahs: comparison of methods and application to MODIS, Int. J. Remote Sens., 28(12), 2753-2775, 2007.

Story, M. and Congalton, R. G.: Accuracy assessment: a user's perspective, Photogrammm. Eng. Rem. S., 52, 397-399, 1986

$\mathrm{Su}$, L.: Optimising support vector machine learning for semi-arid vegetation mapping by using clustering analysis, ISPRS J. Photogramm., 64, 407-413, 2009 
Sunar, F. and Ozkan, C.: Forest fire analysis with remote sensing data, Int. J. Remote Sens., 22(12), 2265-2277, 2001

Tansey, K., Grégoire, J. M. C., Defourny, P., Leigh, R., Pekel, van Bogaert, E., Bartholomé, E., and Bontemps, S.: A new, global, multi-annual (2000-2007) burnt area product at $1 \mathrm{~km}$ resolution and daily intervals, Geophys. Res. Lett., 35, L01401, doi:10.1029/2007GL031567, 2008.

Thome, K.: Algorithm Thoretical Basis document for ASTER Surface radiance and ASTER Surface Reflectance products, available at: http://www.science.aster.ersdac.or.jp/en/documnts/pdf/ 2b0105.pdf last access: 14 April 2009), 1999.

Tseng, M.-H., Chen, S.-J., Hwang, G.-H., and Shen, M.-Y.: A genetic algorithm rule-based approach for land cover classification, ISPRS J. Photogramm., 63, 202-21, 2008

van der Linden, S., Janz, A., Waske, B., Eiden, M., and Hostert, P.: Classifying segmented hyperspectral data from a heterogeneous urban environment using support vector machines, J. Appl. Remote Sens., 1, 013543, doi:10.1117/1.2813466, 2007.
Van Wagtendonk, J. W., Root, R. R., and Key, C. C.: Comparison of AVIRIS and Landsat ETM+ detection capabilities for burn severity, Remote Sens. Environ., 92, 397-408, 2004.

Vapnik, V.: Statistical Learning Theory, Wiley, New York, 1998.

Waske, B. and Benediktsson, J.A.: Fusion of support vector machines for classification of multisensor data, IEEE T. Geosci. Remote Se., 45(12), 3858-3866, 2007.

WWF Hellas: Mt Parnitha National park burnt area mapping using IKONOS imagery, available at: http://www.wwf.gr/index.php? option=com_content $\backslash \&$ task=view $\backslash$ \&id=539 $\backslash \&$ itemid=294 (last access:14 April 2009), 2007.

Yuksel, A., Akay, A. E., and Gundogan R.: Using ASTER imagery in Land use/Cover classification of eastern Mediterranean landscapes according to CORINE land cover project, Sensors, 8 , 1237-1251, 2008.

Zammit, O. Descombes, X., and Zeruba, J.: Burnt area mapping using Support Vector machines, Forest Ecol. Manag., 234, S240S249, 2006.

Zhu, G. and Blumberg, D. G.: Classification using ASTER data and SVM algorithms; The case study of Beer Sheva, Israel, Remote Sens. Environ., 80, 233-240, 2002. 